\title{
Análise da Gestão Estratégica de Custos e Métodos de Custeio tradicionais em uma Indústria Têxtil Paraibana
}

Ana Cláudia Rodrigues Graduação em Ciências Contábeis pela Universidade Federal da Paraíba - UFPB

E-mail: claudiarodriguesufpb@gmail.com

Vera Lúcia Cruz Doutorado em andamento em Administração pela Universidade Potiguar - UnP Professora Assistente da Universidade Federal da Paraíba - UFPB E-mail:veralc22@hotmail.com

Ramon Rodrigues dos Santos Mestrado em Administração pela Universidade Federal da Paraíba - UFPB Professor da Universidade Federal de Pernambuco - UFPE E-mail: ramonrdgs@gmail.com

Rodrigo José Guerra Leone Doutorado em Engenharia de Sistemas e Computação pela Universidade Federal do Rio de Janeiro - UFRJ Professor do Mestrado em Administração da Universidade Potiguar - UnP E-mail: rodrigo.leone@gestorfp.com.br

\section{RESUMO}

Este trabalho tem como objetivo geral analisar, dentre os métodos de custeio tradicionais, o que melhor atendeu a demanda de informações de custos em uma empresa têxtil paraibana de médio porte. A metodologia desta pesquisa foi caracterizada como estudo de caso, junto a uma pesquisa dentro da empresa a respeito dos seus gastos de produção, por meio de diversas visitas ao setor produtivo para o melhor entendimento de todo esse processo e para que todos os gastos fossem atribuídos de forma correta. De acordo com os resultados, a empresa utiliza o método de custeio por absorção, visto que está agregando valores que não representam verdadeiramente a realidade dos custos do produto, pois parte-se de uma base de classificação de custos diferenciada. Dessa forma, concluiu-se, a partir da análise dos dados coletados, que a empresa poderá mudar o método utilizado, para que a gestão estratégica de custos seja eficaz, gerando informações viáveis e podendo, assim, ajudar na gestão da empresa.

Palavras-chave: Gestão Estratégica de Custos. Custeio Variável. Custeio por Absorção. 


\section{ABSTRACT}

This work has as general objective to analyze, among traditional costing methods, which best met the demand for cost information in a medium-sized textile company in Paraíba, Brazil. The methodology of this research was characterized as a case study, together with a research within the company regarding its production expenses, through several visits to the productive sector for a better understanding of this whole process and for all expenses to be attributed correct form. According to the results, the company uses the absorption cost method, since it is aggregating values that do not truly represent the reality of the costs of the product, because it starts from a differentiated cost classification base. Thus, it was concluded, from the analysis of the collected data, that the company can change the method used, so that the strategic management of costs is effective, generating viable information, and thus help in the management of the company.

Keywords: Strategic Cost Management. Variable Costing. Absorption Costing.

\section{INTRODUÇÃO}

O mercado competitivo tende a fazer com que as empresas busquem cada vez mais elaborar estratégias para permanecerem atuando e melhorando sua posição em seus setores. Neste contexto, a indústria brasileira passou por uma reestruturação competitiva e, entre as mudanças, houve a inserção das ferramentas informacionais nas empresas; com isso, a contabilidade, quando utilizada da maneira correta, pode ser um diferencial desse setor.

Dentre as divisões da contabilidade, encontra-se a de custos que, segundo Leone e Leone (2010), "se assemelha a um processador de informações no qual os dados são recebidos, acumulados, analisados e interpretados, transformando-os em informações de custos para os diversos níveis gerenciais". Neste fluxo, as informações passadas devem ser apresentadas em uma base sólida, para que seja usada posteriormente em todo o planejamento empresarial.

Os gastos são umas das maiores preocupações dos gestores; logo, há uma busca constante para tentar reduzi-los. Neste aspecto, a contabilidade de custos é necessária para todo esse processo, visto que a contabilidade serve de suporte para a 
sustentação de uma gestão eficiente na busca de informações relevantes. Neste contexto, existem algumas ferramentas e metodologias utilizadas pela contabilidade de custos e pela respectiva gestão estratégica que objetivam orientar e auxiliar os gestores na composição de estratégias e na tomada de decisão.

Com a evolução na indústria têxtil e com as dificuldades competitivas que este setor vem enfrentando em relação às particularidades tecnológicas, a evolução mundial do setor foi desigual no que diz respeito à organização da produção: os rumos seguiram a vertente de organizações mais adaptáveis, inserindo técnicas como grupos de trabalho, círculos de qualidade e just in time.

De acordo com Figueiredo, Cruz, Meireles, Peixoto e Paulino (2014), "as empresas necessitam alocar seus custos de forma coerente e buscar, em sua apuração, informações que lhe sejam úteis, não só para controle de estoque, mas que Ihe auxiliem a traçar estratégias". A necessidade de uma estratégia de custos é fundamental para que as empresas tenham um desempenho favorável no decorrer de sua operacionalidade.

Entretanto, algumas empresas tendem a negligenciar os métodos de custeio, trazendo com isso um atraso para seu desenvolvimento. Logo, qualquer entidade que almeje o seu crescimento e êxito, respondendo a qualquer erro de percurso, preocupase em aplicar da melhor forma possível o controle de custos, identificando um método de custeio que possa auxiliá-lo em suas necessidades.

Além disso, as possibilidades de utilização dos fatores de produção costumam determinar uma variedade no comportamento dos custos. Com isso, uma empresa que apresente um sistema de custos tende a apresentar um diferencial frente aos seus concorrentes.

Diante dessa problemática, chega-se ao problema de pesquisa: Como os métodos de custeio utilizados em uma indústria têxtil podem gerar informações para auxiliar sua gestão estratégica de custos? Com este estudo, procura-se apresentar como os métodos de custeio geram informações para gestão estratégica de custos em uma indústria têxtil paraibana. 


\section{REVISÃO DA LITERATURA}

\subsection{Métodos de Custeio}

Os métodos de custeio encontrados na literatura tendem para o atendimento das necessidades específicas; em alguns casos, costumam ser utilizados mais de um método simultaneamente, buscando sempre identificar qual dentre eles se identifica melhor com a realidade da empresa: de acordo com a necessidade de informação, a empresa utiliza o meio mais adequado para o seu desempenho operacional.

Segundo Abbas, Gonçalves e Leoncine (2012), esses métodos são utilizados, entre muitas outras informações, para determinar o valor dos objetos de custeio; reduzir custos, melhorar os processos; eliminar desperdícios; decidir entre produzir ou terceirizar; eliminar, criar e aumentar, ou diminuir a linha de produção de certos produtos.

Nesse contexto, com a utilização correta desses métodos, a empresa poderá se beneficiar com as seguintes informações: determinar o valor dos objetos de custeio; reduzir os custos, melhorar no processo produtivo; decidir entre produzir e/ou terceirizar; e eliminar, criar, aumentar, ou diminuir a linha de produção de determinados produtos.

O primeiro método destacado neste trabalho, o custeio variável, utiliza somente os elementos variáveis para os custos dos produtos. Esse método é indicado especialmente para controles gerenciais; esse custeio possibilita à administração informações a respeito dos custos variáveis, ignora os custos fixos, que são tratados como despesas. Esse método é conhecido como método de custeio direto.

A variação dos elementos na produção de um produto tem relação direta com o método de custeio utilizado por esta para apropriação de informações relevantes. Portanto, o custeio variável costuma ser uma ferramenta útil, pois apresenta pontos que podem ajudar na tomada de decisão, principalmente as que consistem em alocar um fator escasso de produção aos vários produtos, com o objetivo de obter maior lucratividade. 
Já o método de custeio por absorção é uma das mais antigas metodologias de custeio e ainda presente nos dias atuais. É o método mais utilizado pelas empresas. Segundo Santos (2009), esse método é considerado básico para a avaliação de estoques pela contabilidade societária para fins de levantamento do balanço patrimonial e da demonstração do resultado do exercício.

Nesse método de custeio, os custos fixos têm um papel preponderante, pois eles devem ser manuseados de maneira cuidadosa para serem alocados de forma correta ao produto. Alguns autores como Crepaldi (2008) e Moura (2005) enfatizam a utilização desse sistema de custeio nas empresas, mesmo com a dificuldade em ratear os custos indiretos de fabricação sem arbitrariedade, sobretudo pela aceitação do fisco.

O custeio por absorção destina-se a auxiliar a gestão no processo de determinação da rentabilidade e de avaliação patrimonial da empresa. A funcionalidade do custeio vai depender principalmente dos objetivos da organização. A separação dos gastos em custos e despesas faz com que o método de custeio por absorção apresente exatamente o gasto que está diretamente ligado ao produto.

No que se refere à sua aplicação, apesar de suas limitações, "há vantagens em utilizar esse tipo de custeio, no que diz respeito à melhora na utilização desses recursos, por exemplo, onde ele proporciona a apuração dos custos totais por produto" (Figueiredo et al. 2014). Portanto, esses custos são separados por diretos e indiretos para que, a partir disso, seja feito o seu devido rateio. As despesas irão posteriormente à apuração dos custos.

\subsection{Custeio Variável versus Custeio por Absorção}

O Quadro 1 destaca semelhanças e diferenças entre os métodos de custeio variável e por absorção. 
Análise da Gestão Estratégica de Custos e Métodos de Custeio tradicionais em uma Indústria

Têxtil Paraibana

Ana Claudia Rodrigues da Silva, Vera Lucia Cruz, Ramon Rodrigues dos Santos, Rodrigo José Guerra

Leone

\begin{tabular}{|c|c|}
\hline Custeio Variável & Custeio por Absorção \\
\hline 1 - Classifica os custos em fixos e variáveis. & $\begin{array}{l}1 \text { - Não há a preocupação em classificar custos } \\
\text { fixos e variáveis. }\end{array}$ \\
\hline $\begin{array}{l}2 \text { - Os resultados apresentados sofrem } \\
\text { influência direta do volume de produção. }\end{array}$ & $\begin{array}{l}2 \text { - Os resultados apresentados sofrem influência } \\
\text { direta do volume de vendas. }\end{array}$ \\
\hline $\begin{array}{l}3 \text { - Aparentemente, sua filosofia básica alia-se } \\
\text { aos preceitos geralmente aceitos de } \\
\text { contabilidade, principalmente os fundamentos } \\
\text { do regime de competência. }\end{array}$ & $\begin{array}{l}3 \text { - Aparentemente sua filosofia básica contraria } \\
\text { os preceitos geralmente aceitos de contabilidade, } \\
\text { principalmente os fundamentos do regime de } \\
\text { competência. }\end{array}$ \\
\hline $\begin{array}{l}\text { ição marginal diferença } \\
\text { ıstos diretos e variáveis }\end{array}$ & $\begin{array}{l}4-\text { Apr } \\
\text { entre as } \\
\text { do segm }\end{array}$ \\
\hline $\begin{array}{l}5 \text { - O custeamento variável destina-se a auxiliar, } \\
\text { sobretudo, a gerência no processo de } \\
\text { planejamento e de tomada de decisões. }\end{array}$ & $\begin{array}{l}5-\mathrm{O} \\
\text { auxiliar } \\
\text { da renta }\end{array}$ \\
\hline $\begin{array}{l}6 \text { - Como o custeamento variável trata dos } \\
\text { custos diretos e variáveis de determinado } \\
\text { segmento, o controle da absorção dos custos } \\
\text { da capacidade ociosa não é bem explorado. }\end{array}$ & $\begin{array}{l}6 \text { - Como o custeamento por absorção trata dos } \\
\text { custos diretos e indiretos de determinado } \\
\text { segmento, sem cogitar de perquirir se os custos } \\
\text { são variáveis ou fixos, apresenta melhor visão } \\
\text { para o controle da absorção dos custos da } \\
\text { capacidade ociosa. }\end{array}$ \\
\hline
\end{tabular}

Quadro 1. Comparação entre os Métodos Variável e por Absorção

Fonte: Martins (2010).

De acordo com o Quadro 1, existem comparações entre os dois métodos de custeio variável e custeio por absorção, cabendo à organização adequar-se aos métodos que irão utilizar para melhorar seu desempenho. Desta maneira, ao demonstrar as semelhanças e diferenças entre dois métodos de custeio, segundo Martins (2010), confirma-se que os mesmos são complementares, devido ao fornecimento de informações para a tomada de decisão e também atendem aos princípios contábeis e fiscais. Com isso, entende-se que uma junção dos métodos de custeio variável e por absorção pode trazer uma possibilidade ainda maior de identificar os gastos da empresa e, a partir delas, usá-las na tomada de decisão. 
Análise da Gestão Estratégica de Custos e Métodos de Custeio tradicionais em uma Indústria

Têxtil Paraibana

Ana Claudia Rodrigues da Silva, Vera Lucia Cruz, Ramon Rodrigues dos Santos, Rodrigo José Guerra

Leone

\section{METODOLOGIA}

\subsection{Procedimentos Metodológicos}

Para a realização deste estudo, o método utilizado foi o estudo de caso, associado a uma pesquisa documental, visto que foi utilizado o acervo de informações da empresa estudada, por meio de suas planilhas e dados, como os demonstrativos dos gastos industriais, por exemplo.

Com relação à abordagem dos objetivos listados, a pesquisa apresentou, em sua essência, uma abordagem qualitativa e quantitativa, devido à utilização de meios de coleta e análise dos dados, organizados e calculados em planilhas eletrônicas para a obtenção da apuração dos resultados e, posteriormente, para serem analisados.

A indústria-caso está localizada na Paraíba, cujo processo produtivo consiste desde a compra do algodão e poliéster até o fio de algodão acabado, conforme a cor solicitada pelo cliente. $O$ processo produtivo ocorre em dois galpões: um responsável pelo processo denominado "desfibragem" e o outro pela produção do fio. A Tabela 1 relaciona todos os produtos que foram confeccionados em 2015 na respectiva empresa.

Tabela 1

Produtos Confeccionados no Ano

\begin{tabular}{c|c}
\hline Produto & Quantidade Produzida (Kg) \\
\hline A & 1.507 .792 \\
\hline B & 1.500 .001 \\
\hline C & 465.633 \\
\hline D & 765.845 \\
\hline E & 564.987 \\
\hline F & 142.765 \\
\hline G & 567.876 \\
\hline H & 1.498 .367 \\
\hline TOTAL & $\mathbf{7 . 0 1 3 . 2 6 6}$ \\
\hline
\end{tabular}

Nota. Fonte: Elaboração própria.

Devido à grande quantidade de produtos, a amostra do estudo se caracterizou 
Análise da Gestão Estratégica de Custos e Métodos de Custeio tradicionais em uma Indústria

Têxtil Paraibana

Ana Claudia Rodrigues da Silva, Vera Lucia Cruz, Ramon Rodrigues dos Santos, Rodrigo José Guerra

em analisar o processo produtivo dos três produtos mais confeccionados e solicitados durante o ano-base de estudo desta pesquisa, conforme mostra a Tabela 2.

Tabela 2

Produtos e Cores Utilizados na Pesquisa

\begin{tabular}{c|l|c|c}
\hline PRODUTOS & \multicolumn{1}{|c|}{ COMPOSIÇÃO } & CORES & PRODUÇÃO (KG) \\
\hline A & $\begin{array}{l}\text { DESFIBRADOS, POLIÉSTER, } \\
\text { ALGODÃO E PIOLHO NOBRE } \\
\text { BATIDO }\end{array}$ & BRANCO & 1.507 .792 \\
\hline B & $\begin{array}{l}\text { DESFIBRADOS, POLIÉSTER, } \\
\text { ALGODÃO E PIOLHO }\end{array}$ & CINZA & 1.500 .001 \\
\hline $\mathrm{H}$ & $\begin{array}{l}\text { DESFIBRADOS, POLIÉSTER, } \\
\text { ALGODÃO E PIOLHO F8 }\end{array}$ & $\begin{array}{c}\text { MIL } \\
\text { CORES }\end{array}$ & 1.498 .367 \\
\hline
\end{tabular}

Nota. Fonte: Elaboração própria.

H.

Conforme mostra a Tabela 2, serão estudados os custos de três produtos: A, B e

\subsection{Coleta e Análise de Dados}

Os dados da empresa estudada são referentes ao ano de 2015, coletados pelos sistemas contábeis e gerenciais da indústria e organizados em planilhas eletrônicas, quais sejam: gastos incorridos em todas as etapas da produção do produto; atividades interligadas à produção que geram custos aos produtos; lista com relação dos salários dos funcionários ligados à produção; balancete contábil, matéria-prima gasta na execução do processo, planilha com apuração dos custos e descrição de todo o processo produtivo. No que se refere aos custos indiretos, foi observado, no balancete, a existência dos custos descritos na Tabela 3. 
Análise da Gestão Estratégica de Custos e Métodos de Custeio tradicionais em uma Indústria

Têxtil Paraibana

Ana Claudia Rodrigues da Silva, Vera Lucia Cruz, Ramon Rodrigues dos Santos, Rodrigo José Guerra

Leone

Tabela 3

Custos Indiretos de Fabricação (Valores em R\$)

\begin{tabular}{l|c}
\hline \multicolumn{2}{c}{ CIF } \\
\hline & VALOR \\
Força e Luz & $\mathrm{R} \$ 3.971 .479,31$ \\
MOI & $\mathrm{R} \$ 2.320 .910,64$ \\
Depreciação & $\mathrm{R} \$ 1.358 .422,91$ \\
Reposição Mecânica & $\mathrm{R} \$ 375.740,61$ \\
Refeitóio & $\mathrm{R} \$ 161.745,44$ \\
Assistência Técnica - PJ & $\mathrm{R} \$ 138.494,15$ \\
Reposição Elétrica & $\mathrm{R} \$ 64.183,24$ \\
Transporte do Pessoal & $\mathrm{R} \$ 60.684,29$ \\
Reposição Correias & $\mathrm{R} \$ 57.777,95$ \\
Amortização & $\mathrm{R} \$ 46.172,22$ \\
Combustíveis e Lubrificantes & $\mathrm{R} \$ 40.674,96$ \\
Fardamentos e Equipamentos de Segurança & $\mathrm{R} \$ 19.430,69$ \\
Químicos em Geral & $\mathrm{R} \$ 8.543,84$ \\
Conservação e Reparo & $\mathrm{R} \$ 8.234,27$ \\
Telefone, Fax e Internet & $\mathrm{R} \$ 5.234,30$ \\
Material de Limpeza/Copa e Cozinha & $\mathrm{R} \$ 3.315,66$ \\
Material de Expediente & $\mathrm{R} \$ 3.135,21$ \\
Ferramentas & $\mathrm{R} \$ 2.240,36$ \\
Fretes e Carretos & $\mathrm{R} \$ 459,00$ \\
Medicamentos & $\mathrm{R} \$ 107,04$ \\
TOTAL & $\mathbf{R} \$ \mathbf{8 . 6 4 6 . 9 8 6 , 0 9}$ \\
\hline
\end{tabular}

Nota. Fonte: Elaboração Própria.

Conforme a Tabela 3, os gastos com força e luz, MOI, depreciação e reposição mecânica foram considerados as maiores saídas de recursos, gerando, assim, influência significativa nos resultados obtidos. Após a organização, os dados referentes aos custos foram divididos em: Materiais Diretos, Mão de Obra e Custos Indiretos. Para a aplicação dos métodos, inicialmente, foram definidas as atividades que ocorrem no processo produtivo e fora dele.

Os valores finais obtidos foram comparados com o custo encontrado no método por absorção já utilizado pela empresa, e, no custeio variável, após a análise, foram evidenciadas as ferramentas estratégicas de custos para a indústria-caso. 
Análise da Gestão Estratégica de Custos e Métodos de Custeio tradicionais em uma Indústria

Têxtil Paraibana

Ana Claudia Rodrigues da Silva, Vera Lucia Cruz, Ramon Rodrigues dos Santos, Rodrigo José Guerra

\section{RESULTADOS E DISCUSSÕES}

\subsection{Resultados}

Primeiramente, destaca-se que a empresa possui o controle de seus custos aos produtos, sabendo informar quanto custa produzir cada produto e cujo sistema de custeio utilizado é o por absorção, que atende suas necessidades básicas para uma gestão de custos e tomada de decisão.

A soma de todos os gastos envolvidos: o material direto (MD), a Mão de Obra Direta (MOD) e os Custos Indiretos de Fabricação (CIF), além do Custo de Produção (CP) no ano de 2015, é destacada na Tabela 4.

Tabela 4

Custo com Materiais Diretos

\begin{tabular}{c|c|c}
\hline PRODUTO & MATERIAIS DIRETOS & CUSTO MD \\
\hline & $\mathrm{A}$ & $\mathbf{R} \mathbf{2 . 6 4 5 . 9 8 7 , 8 3}$ \\
FIO OEC NE 08/1 T 85\% & $\mathrm{B}$ & $\mathbf{R} \mathbf{2 . 8 6 5 . 8 4 6 , 0 6}$ \\
\cline { 2 - 3 } ALGODAO 15\% POLIÉSTER & $\mathrm{C}, \mathrm{D}, \mathrm{E}, \mathrm{F}, \mathrm{G}$ & $\mathbf{R} \mathbf{2 . 9 8 6 . 5 3 4 , 8 5}$ \\
\cline { 2 - 3 } & $\mathrm{H}$ & $\mathbf{R} \mathbf{3 . 1 0 0 . 6 4 5 , \mathbf { 1 4 }}$ \\
\hline $\begin{array}{c}\text { FIO OEC NE 04/1 T 85\% } \\
\text { ALGODAO 15\% POLIÉSTER }\end{array}$ & TOTAL & $\mathbf{R} \mathbf{1 1 . 5 9 9 . 0 1 3 , 8 8}$ \\
\hline
\end{tabular}

Nota. Fonte: Resultados da Pesquisa (2016).

A Tabela 4 evidencia o consumo do material direto dos produtos que foram levantados nesta pesquisa. Cabe ressaltar que o maior custo, em 2015, segundo os dados, ocorreu durante o quarto trimestre. Já em relação à mão de obra direta (MOD), 108 funcionários estão diretamente ligados ao setor produtivo, operando as máquinas e contribuindo prontamente para o produto final, conforme destaca a Tabela 5. 
Análise da Gestão Estratégica de Custos e Métodos de Custeio tradicionais em uma Indústria

Têxtil Paraibana

Ana Claudia Rodrigues da Silva, Vera Lucia Cruz, Ramon Rodrigues dos Santos, Rodrigo José Guerra

Tabela 5

Distribuição dos Funcionários por Setor Produtivo

\begin{tabular}{l|c}
\hline \multicolumn{1}{c|}{ SETOR } & QUANTIDADE DE FUNCIONÁRIOS \\
\hline DESCARGA & 3 \\
DESFIBRAGEM & 13 \\
FIAÇÃO & 76 \\
ACABAMENTO & 16 \\
TOTAL GERAL DE FUNCIONÁRIOS & 108 \\
\hline
\end{tabular}

Nota. Fonte: Resultados da Pesquisa (2016).

Conforme os dados evidenciados na Tabela 5, 108 funcionários compõem o setor produtivo, separados em turnos de 8 horas diárias e totalizando, assim, uma produção ininterrupta durante as 24 horas. Para calcular o custo do produto pelo método de custeio variável, foram considerados apenas os custos e as despesas variáveis. A Tabela 6 apresenta as despesas variáveis (DV) por produto.

Tabela 6

Despesas variáveis por produto (Valores em $\mathbf{R} \$$ )

\begin{tabular}{c|c|c|c}
\hline PRODUTO & CUSTO UNITÁRIO & $\begin{array}{c}\text { UNIDADES } \\
\text { FABRICADAS }\end{array}$ & DV TOTAL \\
$\mathrm{A}$ & $\mathrm{R} \$ 0,44$ & 1.507 .792 & $\mathrm{R} \$ 665.694,23$ \\
$\mathrm{~B}$ & $\mathrm{R} \$ 0,42$ & 1.500 .001 & $\mathrm{R} \$ 637.856,06$ \\
$\mathrm{H}$ & $\mathrm{R} \$ 0,39$ & 1.498 .367 & $\mathrm{R} \$ 597.765,64$ \\
\hline
\end{tabular}

Nota. Fonte: Resultados da Pesquisa (2016).

A Tabela 6 mostra as despesas variáveis que se referem aos gastos com os departamentos que não estão relacionados com a produção e outras despesas gerais da empresa por produto. Multiplicando o gasto unitário com as unidades fabricadas, obtém-se o total gasto por produto. No caso dos custos variáveis, esses são as maiores demandas da empresa. $\mathrm{Na}$ Tabela 7 , identificamos os custos variáveis (CV) por produto. 
Análise da Gestão Estratégica de Custos e Métodos de Custeio tradicionais em uma Indústria

Têxtil Paraibana

Ana Claudia Rodrigues da Silva, Vera Lucia Cruz, Ramon Rodrigues dos Santos, Rodrigo José Guerra

Tabela 7

Custos variáveis por produto (Valores em $\mathbf{R} \$$ )

\begin{tabular}{c|c|c|c}
\hline PRODUTO & CUSTO UNITÁRIO & $\begin{array}{c}\text { UNIDADES } \\
\text { FABRICADAS }\end{array}$ & CV TOTAL \\
\hline $\mathrm{A}$ & $\mathrm{R} \$ 2.43$ & 1.507 .792 & $\mathrm{R} \$ 3.661 .281,48$ \\
$\mathrm{~B}$ & $\mathrm{R} \$ 1,99$ & 1.500 .001 & $\mathrm{R} \$ 2.954 .876,35$ \\
$\mathrm{H}$ & $\mathrm{R} \$ 1,90$ & 1.498 .367 & $\mathrm{R} \$ 2.843 .654,56$ \\
\hline
\end{tabular}

Nota. Fonte: Resultados da Pesquisa (2016).

Os custos variáveis demonstrados na Tabela 7 referem-se aos gastos como material direto, energia e combustíveis, entre outros. Na sequência, a Tabela 8 apresenta o custo unitário de acordo com o método de custeio variável.

Tabela 8

Custeio Variável (Valores em R\$)

\begin{tabular}{c|c|c|c|c|c}
\hline PRODUTO & CV & DV & CUSTO TOTAL & $\begin{array}{c}\text { UNIDADES } \\
\text { FABRICADAS }\end{array}$ & $\begin{array}{c}\text { CUSTO } \\
\text { UNITÁRIO }\end{array}$ \\
\hline & & & & & \\
$\mathrm{A}$ & $\mathrm{R} \$ 3.661 .281,48$ & $\mathrm{R} \$ 665.694,23$ & $\mathrm{R} \$ 4.326 .975,71$ & 1.507 .792 & $\mathrm{R} \$ 2.87$ \\
$\mathrm{~B}$ & $\mathrm{R} \$ 2.954 .876,35$ & $\mathrm{R} \$ 637.856,06$ & $\mathrm{R} \$ 3.592 .732,41$ & 1.500 .001 & $\mathrm{R} \$ 2,40$ \\
$\mathrm{H}$ & $\mathrm{R} \$ 2.843 .654,56$ & $\mathrm{R} \$ 597.765,64$ & $\mathrm{R} \$ 3.441 .420,20$ & 1.498 .367 & $\mathrm{R} \$ 2,29$ \\
\hline
\end{tabular}

Nota. Fonte: Resultados da Pesquisa (2016).

Como demonstra a Tabela 8, a soma dos custos variáveis com as despesas variáveis resulta no custo total do produto, com o qual, dividido pelas unidades fabricadas, obtém-se o custo unitário do produto. Para calcular o custo do produto pelo método de custeio por absorção, foram considerados todos os custos. 
Por não ser viável a atribuição dos custos indiretos de fabricação e a mão de obra direta de forma precisa aos produtos, estes precisaram ter seus valores rateados aos produtos. Considerando que o tipo de atividade da empresa está relacionado ao processo de fabricação, foi considerado como base de rateio nas horas trabalhadas para fabricação do produto, sabendo-se que a receita da entidade está ligada diretamente à necessidade do trabalho realizado pelos seus empregados do setor produtivo. Na Tabela 9, é apresentado o rateio dos CIF aos produtos:

Tabela 9

Rateio CIF (Valores em R\$)

\begin{tabular}{c|c|c|c|c|c}
\hline PRODUTO & DESCARGA & DESFIBRAGEM & FIAÇÃO & ACABAMENTO & CIF \\
\hline $\mathrm{A}$ & $\mathrm{R} \$ 40.895,75$ & $\mathrm{R} \$ 176.969,72$ & $\mathrm{R} \$ 1.035 .191,97$ & $\mathrm{R} \$ 218.012,57$ & $\mathrm{R} \$ 1.471 .070,01$ \\
$\mathrm{~B}$ & $\mathrm{R} \$ 30.771,07$ & $\mathrm{R} \$ 133.156,84$ & $\mathrm{R} \$ 778.906,64$ & $\mathrm{R} \$ 164.038,61$ & $\mathrm{R} \$ 1.106 .873,16$ \\
$\mathrm{H}$ & $\mathrm{R} \$ 29.016,76$ & $\mathrm{R} \$ 125.565,34$ & $\mathrm{R} \$ 734.499,86$ & $\mathrm{R} \$ 154.686,49$ & $\mathrm{R} \$ 1.043 .768,45$ \\
\hline
\end{tabular}

Nota. Fonte: Resultados da Pesquisa (2016).

A Tabela 9 evidencia o rateio do CIF aos produtos, que tiveram seus valores alocados com base nas horas trabalhadas na fabricação dos mesmos. Foi utilizado o mesmo critério para o rateio dos gastos com MOD aos produtos, como mostra a Tabela 10. 
Análise da Gestão Estratégica de Custos e Métodos de Custeio tradicionais em uma Indústria

Têxtil Paraibana

Ana Claudia Rodrigues da Silva, Vera Lucia Cruz, Ramon Rodrigues dos Santos, Rodrigo José Guerra

Tabela 10

Rateio MOD (Valores em R\$)

\begin{tabular}{c|c|c|c|c|c}
\hline PRODUTO & DESCARGA & DESFIBRAGEM & FIAÇÃO & ACABAMENTO & MOD \\
\hline $\mathrm{A}$ & $\mathrm{R} \$ 18.367,22$ & $\mathrm{R} \$ 79.481,15$ & $\mathrm{R} \$ 464.928,39$ & $\mathrm{R} \$ 97.914,43$ & $\mathrm{R} \$ 660.691,19$ \\
$\mathrm{~B}$ & $\mathrm{R} \$ 17.998,55$ & $\mathrm{R} \$ 77.885,80$ & $\mathrm{R} \$ 455.596,32$ & $\mathrm{R} \$ 95.949,09$ & $\mathrm{R} \$ 647.429,76$ \\
$\mathrm{H}$ & $\mathrm{R} \$ 16.973,12$ & $\mathrm{R} \$ 73.448,41$ & $\mathrm{R} \$ 459.639,64$ & $\mathrm{R} \$ 90.482,59$ & $\mathrm{R} \$ 640.543,76$ \\
\hline
\end{tabular}

Nota. Fonte: Resultados da Pesquisa (2016).

A Tabela 10 apresenta o rateio da MOD aos produtos, com base nas horas trabalhadas na fabricação dos mesmos, como utilizado anteriormente no custo indireto de fabricação. Com isso, chegamos ao total de MOD de cada produto. $O$ material direto é o principal custo de produção da empresa. Sua base de rateio é feita como os demais: com base nas horas trabalhadas. A Tabela 11 demonstra o rateio realizado no material direto.

Tabela 11

Rateio MD (Valores em R\$)

\begin{tabular}{c|c|c|c|c|c}
\hline PRODUTO & DESCARGA & DESFIBRAGEM & FIAÇÃO & ACABAMENTO & MD \\
\hline A & $\mathrm{R} \$ 76.416,42$ & $\mathrm{R} \$ 330.679,69$ & $\mathrm{R} \$ 1.934 .325,03$ & $\mathrm{R} \$ 407.371,00$ & $\mathrm{R} \$ 2.748 .792,14$ \\
$\mathrm{~B}$ & $\mathrm{R} \$ 63.853,15$ & $\mathrm{R} \$ 276.314,18$ & $\mathrm{R} \$ 1.616 .311,64$ & $\mathrm{R} \$ 340.397,03$ & $\mathrm{R} \$ 2.296 .876$ \\
$\mathrm{H}$ & $\mathrm{R} \$ 62.568,29$ & $\mathrm{R} \$ 270.754,16$ & $\mathrm{R} \$ 1.586 .788,02$ & $\mathrm{R} \$ 330.547,51$ & $\mathrm{R} \$ 2.250 .657,98$ \\
\hline
\end{tabular}

Nota. Fonte: Resultados da Pesquisa (2016).

Como demonstrado na Tabela 11, os maiores custos com material direto estão no processo de fiação, cujo produto é efetivamente produtivo. A Tabela 12 evidencia o custo do produto com base no método de custeio por absorção. 
Análise da Gestão Estratégica de Custos e Métodos de Custeio tradicionais em uma Indústria

Têxtil Paraibana

Ana Claudia Rodrigues da Silva, Vera Lucia Cruz, Ramon Rodrigues dos Santos, Rodrigo José Guerra

Tabela 12

Custeio por Absorção (Valores em R\$)

\begin{tabular}{c|c|c|c|c|c|c}
\hline PRODUTO & MD & MOD & CIF & $\begin{array}{c}\text { CUSTO } \\
\text { TOTAL }\end{array}$ & $\begin{array}{c}\text { UNIDADES } \\
\text { FABRICADAS }\end{array}$ & $\begin{array}{c}\text { CUSTO } \\
\text { UNITÁRIO }\end{array}$ \\
\hline $\mathrm{A}$ & $2.748 .792,14$ & $660.691,19$ & $1.471 .070,01$ & $4.880 .553,34$ & 1.507 .792 & $\mathrm{R} \$ 3,23$ \\
$\mathrm{~B}$ & 2.296 .876 & $647.429,76$ & $1.106 .873,16$ & $4.051 .178,9$ & 1.500 .001 & $\mathrm{R} \$ 2,71$ \\
$\mathrm{H}$ & $2.250 .657,98$ & $640.543,76$ & $1.043 .768,45$ & $3.934 .970,19$ & 1.498 .367 & $\mathrm{R} \$ 2,62$ \\
\hline
\end{tabular}

Nota. Fonte: Resultados da Pesquisa (2016).

Conforme evidencia a Tabela 12, a soma dos gastos com material direto, mão de obra direta e CIF resulta no custo total do produto; estes necessitaram ser rateados para, posteriormente, serem alocados aos produtos. Dividindo-se o custo total do produto pelas unidades fabricadas, encontra-se o custo unitário do produto.

\subsection{Análise dos Resultados}

O presente estudo buscou, com base nos dados levantados, comparar os custos dos produtos pelos diferentes métodos: o custeio variável e o custeio por absorção. Os valores encontrados com a aplicação dos dois métodos de custeio na empresa são divergentes com a utilização de todos os dados coletados e suas devidas aplicações, cujos valores estão demonstrados no Gráfico 1. 


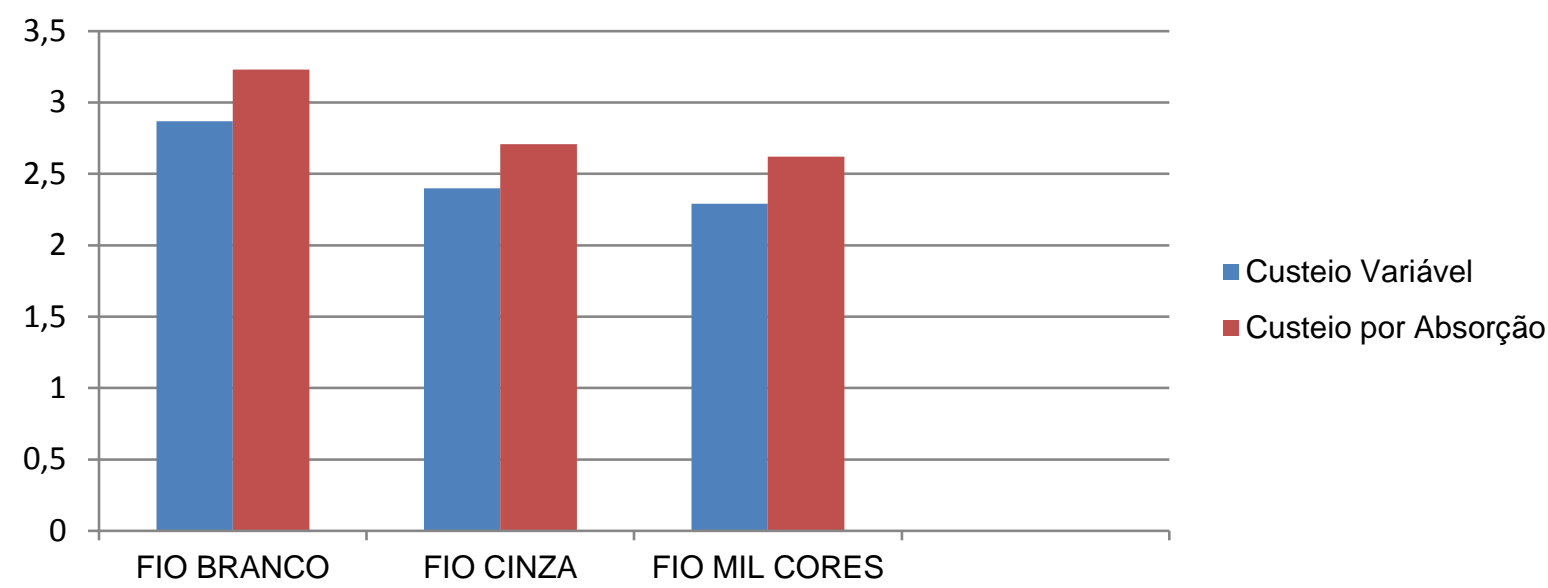

Gráfico 1. Comparação dos Métodos de Custeio Fonte: Elaboração própria.

Analisando o Gráfico 1, evidencia-se que a forma de custo que está sendo aplicada na empresa é o método de custeio por absorção, apresentando valores mais elevados, tendo em vista que parte de uma base de classificação geralmente não representa a realidade dos custos relacionados ao produto. Observa-se que os custos relacionados ao custeio por absorção e variável estão alinhados, diferindo apenas a forma de como o método determina seu critério de identificação e classificação.

Buscando-se atender as necessidades da gestão, o custeio por absorção demonstra a rentabilidade do produto e serve para a confecção do preço de venda base, porém o método de custeio variável apresenta-se como a melhor alternativa para este caso, isto porque, além de demonstrar se o produto está sendo rentável, esse exclui custos fixos como, por exemplo, a mão de obra, depreciação das máquinas, amortização, material de limpeza, telefone, manutenção, conservação e reparo, custos esses que se alteram significativamente no resultado, apresentando, assim, uma maior aproximação da realidade dos gastos da empresa com os produtos.

A boa gestão de custos está na modificação comportamental estruturada na prática, na conferição de uma nova alternativa instrutiva de custos e na mudança de 
processos. Compromete-se com a eficiência pela redução dos gastos, por meio de estudos e análises voltados para a mudança de processos.

O desenvolvimento da gestão de custos, com enfoque estratégico, auxilia para que a empresa se diferencie da concorrência, considerando a sua capacidade de competir, melhorar seu processo produtivo e de planificar suas ações. Uma gestão de custos eficaz está na busca da diminuição e na contenção de gastos no processo produtivo e geral da empresa. Isso somente é possível caso a gestão empresarial esteja atenta a todo o seu processo produtivo, seu chão de fábrica, seus gastos mensais fora dessa área. A partir desse conhecimento, será necessário estar aberto a mudanças trazidas pelos sistemas de custeio.

Com base nos dados coletados, o método do custeio variável forneceu, neste caso, ferramentas que podem auxiliar no controle dos custos para esta empresa, estrategicamente fornecendo as informações dos custos que mostrarão a influência de tal ação e o que as alternativas envolvidas nas decisões provocarão no custo total.

Portanto, o custeio variável traz efetiva avaliação do resultado direto, sem a interferência dos custos e despesas fixas, os quais são demonstrados como custos sustentáveis da organização, inteirando o gestor com informações mais detalhadas dos custos de seus produtos.

\section{CONSIDERAÇÕES FINAIS}

Esta pesquisa teve como propósito, mediante um estudo de caso em uma indústria têxtil localizada na Paraíba, apresentar como o método de custeio gera informações para uma gestão estratégica de custos desenvolvida pela empresa.

$\mathrm{Na}$ aplicação dos métodos, observou-se que o por absorção atribui aos custos valores que podem não estar refletindo a realidade dos custos dos produtos fabricados na empresa, pois parte de um suporte de classificação que não muito adequado para apurar a veracidade dos custos, quando, na maioria das vezes, existe uma arbitrariedade nessa separação. 
Os métodos de custeio por absorção e variável se exprimiram de forma mais coesa em relação à apuração dos gastos relacionados ao produto. Estes retratam seus custos compondo a realidade de cada mercadoria, distinguindo-se apenas na forma como o método estabelece seu critério de identificação e classificação de custos.

Dessa forma, concluiu-se, a partir da análise dos dados coletados, que o método utilizado pela empresa gera informações relevantes para a gestão estratégica de custos, porém o método do custeio variável gerou efetivamente a realidade de seus gastos, atendendo assim também uma gestão estratégica de custos na empresa.

\section{REFERÊNCIAS}

Abbas, K., Gonçalves, M. N., \& Leoncine, M. (2012). Os métodos de custeio: vantagens, desvantagens e sua aplicabilidade nos diversos tipos de organizações apresentadas pela literatura. Contexto, 12 (22), 145-159.

Crepaldi S. A. (2008). Contabilidade Gerencial: Teoria e Prática. (4a ed). São Paulo: Atlas.

Cunha, P. R. da, Beuren, I. M., Rausch, R. B., \& Benvenutti, D. (2009). Abrangência da contabilidade gerencial segundo os docentes de contabilidade de Santa Catarina Brasil. Revista Digital del Instituto Internacional de Costos, (5), 191-211.

Figueiredo, T. L., Cruz, V. L., Meireles, J. M. da S., Peixoto, E. P. de A., \& Paulino, G. C. (2014, novembro). Aplicação do custeio abc na geração de informações para a tomada de decisão: um estudo de caso em uma indústria têxtil do estado da Paraíba. Congresso Brasileiro de Custos, Natal, RN, Brasil, 21.

Leone, G. S. G. \& Leone, R. J. G. (2010). Curso de Contabilidade de Custos. (4a ed). São Paulo: Atlas.

Martins, E. (2010). Contabilidade de Custos. (10a ed). São Paulo: Atlas.

Moura, H. da S. (2005). O custeio por absorção e o custeio variável: qual seria o melhor método a ser adotado pela empresa? Sitientibus, 32, 129-142.

Santos, J. J. (2009). Contabilidade e análise de custos: modelo contábil, métodos de depreciação, abc: custeio baseado em atividades, análise atualizada de encargos sociais sobre salários. (5a ed). São Paulo: Atlas. 
Análise da Gestão Estratégica de Custos e Métodos de Custeio tradicionais em uma Indústria Têxtil Paraibana

Ana Claudia Rodrigues da Silva, Vera Lucia Cruz, Ramon Rodrigues dos Santos, Rodrigo José Guerra Leone

Data de Submissão: 03/10/2017

Data de Aceite: 19/07/2018 